\title{
CX3CL1 promotes lung cancer cell migration and invasion via the Src/focal adhesion kinase signaling pathway
}

\author{
WANGMI LIU, YUN LIANG, QIAN CHAN, LIBO JIANG and JIAN DONG \\ Department of Orthopedic Surgery, Zhongshan Hospital, Fudan University, Shanghai 200032, P.R. China
}

Received January 22, 2018; Accepted October 22, 2018

DOI: 10.3892/or.2019.6957

\begin{abstract}
The present study investigated the role of $\mathrm{C}-\mathrm{X} 3-\mathrm{C}$ motif chemokine ligand 1 (CX3CL1) in lung cancer cell migration and invasion and its potential mechanism. The expression levels of $\mathrm{C}-\mathrm{X} 3-\mathrm{C}$ motif chemokine receptor 1 (CX3CR1) in six human lung cancer cell lines and one human bronchial epithelial cell line were assessed using reverse transcription-quantitative polymerase chain reaction and western blotting. Cell proliferation was assessed using the Cell Counting Kit- 8 assay. Cell migration and invasion were examined using the Transwell assay, with and without Matrigel, respectively. The signaling pathway activated by CX3CL1 was analyzed via western blotting and inhibitory migration and invasion assays. CX3CR1 was expressed in the six lung cancer cell lines and one normal lung cell line. The lung cancer cell line, H460, was selected for further study. CX3CL1 did not significantly affect H460 proliferation; however, CX3CL1 did significantly enhance the migration and invasion of H460 cells. The Src/focal adhesion kinase (FAK) signaling pathway was activated in a time-dependent manner upon stimulation of CX3CL1. However, blocking Src activity with saracatinib prevented CX3CL1-mediated cell migration and invasion. Therefore, the findings indicated that CX3CL1 promotes lung cancer cell migration and invasion in vitro, and the Src/FAK signaling pathway serves a vital role in this process.
\end{abstract}

\section{Introduction}

The lungs are the leading site of cancer in males. Notably, lung cancer contributes to $17 \%$ of new cancer cases and $23 \%$ of cancer fatalities (1). Due to increases in cigarette smoking and environmental pollution, novel cases and lung cancer-associated mortalities have increased in China (2). Surgery and chemotherapy are two major treatment strategies

Correspondence to: Dr Jian Dong, Department of Orthopedic Surgery, Zhongshan Hospital, Fudan University, 180 Fenglin Road, Shanghai 200032, P.R. China

E-mail: dong.jian@zs-hospital.sh.cn

Key words: non-small cell lung cancer, migration, invasion, Src, focal adhesion kinase, saracatinib for patients with lung cancer, and are performed according to their pathological type (3). However, advancements in therapy have led to improvements in overall survival, and more lung cancer-associated fatalities are ascribed to distant metastases rather than the primary tumor (4). The treatment of metastatic lung cancer has represented a challenge for clinicians and researchers. Unfortunately, the molecular mechanisms underlying lung cancer metastases remain poorly understood. This knowledge gap prevents the development of a potential marker and therapeutic target for lung cancer prediction and treatment, respectively.

Chemokines are classified into four highly conserved groups according to the mutual arrangements of cysteine residues and disulfide bridges: $\mathrm{CXC}, \mathrm{CC}, \mathrm{C}$ and $\mathrm{CX} 3 \mathrm{C}$ (5). As the name suggests, the $\mathrm{CX} 3 \mathrm{C}$ subgroup contains conserved cysteine residues at positions 8, 12, 34 and 50 in humans and other species (6). C-X3-C motif chemokine ligand 1 (CX3CL1), the only member of the $\mathrm{CX} 3 \mathrm{C}$ subgroup, is a transmembrane protein, containing a mucin-like stalk with a chemokine domain on the top and a short intracellular $\mathrm{C}$ terminus on the bottom $(7,8)$.

Since the stalk in this setting appears to serve as a domain extender, the chemokine domain assumes the CX3CL1-C-X3-C motif chemokine receptor 1 (CX3CR1) interaction. There are two forms of CX3CL1, the membrane-attached form and the shed form. Multiple cleavage sites exist in the CX3CL1 stalk structure, which results in multiple distinct shed forms of this chemokine (9). Furthermore, the various shed forms of CX3CL1 may be associated with the specific cell types within the different tissues (10).

As indicated by various studies, the CX3CL1-CX3CR1 interaction is involved in various clinical diseases, including cancer $(11,12)$. However, reports on the clinical role of CX3CL1 in tumors are contradictory because CX3CL1 exerts pro-tumor and antitumor effects. The CX3CL1-CX3CR1 interaction has demonstrated pro-tumor effects in multiple types of cancer, including breast cancer $(12,13)$, B-cell lymphoma, colon (14), ovarian (15), prostate (16), pancreatic (17) and renal cell cancer (18). This discrepancy may be ascribed to the dual functions of CX3CL1 as a chemoattractant for leukocytes and an adhesion molecule for tumor cells. However, there are relatively few studies on the effects of CX3CL1 on lung cancer, let alone the molecular mechanism involved.

In the present study, it was investigated whether CX3CR1 was expressed by the lung cancer cell lines. Experiments were 
performed to investigate the role of CX3CL1 in the proliferation and movement of lung cancer cells. Furthermore, the molecular mechanism was also studied. The findings provide a basis for further study in this field.

\section{Materials and methods}

Cell lines and cell culture. Six human lung cancer cell lines (H1650, H292, H460, A549, HCC827, SK-MES-1) and one human bronchial epithelial cell line (BEAS-2B) were purchased from the Type Culture Collection of the Chinese Academy of Sciences (Shanghai, China). Cell lines were cultivated in Dulbecco's modified Eagle's medium (DMEM) supplemented with $10 \%$ fetal bovine serum (FBS) at $37^{\circ} \mathrm{C}$ in a humidified atmosphere $\left(5 \% \mathrm{CO}_{2} / 95 \%\right.$ air $)$.

$R N A$ isolation and reverse transcription-quantitative polymerase chain reaction (RT-qPCR). TRIzol reagent (Invitrogen; Thermo Fisher Scientific, Inc., Waltham, MA, USA) was used to extract total cellular RNA from the cells. Following this, the total RNA was converted to cDNA with the RT reagent Kit with gDNA Eraser (Takara Bio, Inc., Otsu, Japan) according to the manufacturer's instructions. Subsequently, RT-qPCR was performed using the ABI 7500 Real-Time PCR System (Applied Biosystems; Thermo Fisher Scientific, Inc.). All primers were purchased from Sangon Biotech Co. Ltd. (Shanghai, China) and the sequences were as follows: $\beta$-actin, sense 5'-CAACCGCGAGAAGATGAC CC-3' and antisense 5'-GAGGCGTACAGGGATAGCAC-3'; CX3CR1, sense 5'-AGTGTCACCGACATTTACCTCC-3' and antisense 5'-AAGGCGGTAGTGAATTTGCAC-3. qPCR was performed using SYBR-Green Mix (Takara Bio, Inc.). The following PCR conditions were used: Initial denaturation, 1 cycle of $95^{\circ} \mathrm{C}$ for $30 \mathrm{sec}$, followed by 40 cycles of denaturation at $95^{\circ} \mathrm{C}$ for $5 \mathrm{sec}$, and annealing and extension at $60^{\circ} \mathrm{C}$ for $34 \mathrm{sec}$. Relative quantification of the aforementioned genes was determined using the $2^{-\Delta \Delta C q}$ method with $\beta$-actin as an endogenous control (19).

Immunofluorescence microscopy. Cells were fixed with $4 \%$ paraformaldehyde for $10 \mathrm{~min}$ at room temperature. Following this, cells were rinsed three times with PBS, overlaid with $5 \%$ protease-free bovine serum albumin (Sangon Biotech Co. Ltd.) for $1 \mathrm{~h}$ at room temperature, rinsed with PBS and incubated with primary antibody against CX3CR1 (1:1,000, cat. no. ab8021, Abcam, Cambridge, MA, USA) at $4^{\circ} \mathrm{C}$ overnight. Cells were incubated with fluorescein-conjugated goat anti-rabbit IgG antibody (1:1,000, cat. no. ab150077, Abcam, Cambridge, MA, USA) for $1 \mathrm{~h}$ at room temperature following washing with PBS. Subsequently, cells were washed three times with PBS and mounted in Hoechst solution (cat. no. ab228551; Abcam, Cambridge, MA, USA) for $0.5 \mathrm{~h}$ at room temperature. Slides were viewed with a confocal laser scanning microscope (Leica Microsystems GmbH, Wetzlar, Germany).

Western blotting. Cells were harvested at $80 \%$ confluence using lysis buffer with phosphatase and protease inhibitor cocktails (Cell Lysis Buffer; Cell Signaling Technology, Inc., Danvers, MA, USA). The total protein was detected using BCA methods. Cell lysates containing equivalent amounts of proteins
(30 $\mu \mathrm{g} /$ lane) were subjected to SDS-PAGE using $10 \%$ polyacrylamide gels. Following this, the proteins were transferred onto polyvinylidene difluoride membranes (EMD Millipore, Billerica, MA, USA). The membrane was blocked with 5\% skim milk in Tris-buffered saline with Tween-20 for $1 \mathrm{~h}$ at room temperature. Monoclonal antibodies recognizing CX3CR1 (cat. no. WH0001524M1; Sigma-Aldrich; Merck KGaA, Darmstadt, Germany) and Tubulin (cat. no. AT819; Beyotime Institute of Biotechnology, Haimen, China) were used to blot the membrane at $4^{\circ} \mathrm{C}$ overnight (all 1:1,000). Horseradish peroxidase-conjugated anti-rabbit or anti-mouse $\operatorname{IgG}$ (cat. no. A0208/A0216; Beyotime Institute of Biotechnology) were used as the secondary antibodies to detect the primary antibody for $2 \mathrm{~h}$ at room temperature (1:500). The bands were detected using chemiluminescence reagents (Thermo Fisher Scientific, Inc.). ImageJ $1.51 \mathrm{~m}$ (National Institutes of Health, Bethesda, MD, USA) was used to analyze the bands.

Notably, preliminary experiments with 20-200 nM CX3CL1 treatment (PeproTech, Inc., Rocky Hill, NJ, USA) demonstrated that $100 \mathrm{nM} \mathrm{CX3CL1}$ produced the strongest effect. Therefore, for CX3CL1-induced signaling, cells were stimulated with $100 \mathrm{nmol} / \mathrm{l}$ of CX3CL1 for 15,30 and $60 \mathrm{~min}$. For signaling pathway inhibition, cells were pre-treated with $100 \mathrm{nmol} / 1$ of the Src inhibitor, saracatinib (Selleck Chemicals, Houston, TX, USA), for $1 \mathrm{~h}$ prior to stimulation with the same amount of CX3CL1 for 15, 30 and $60 \mathrm{~min}$. Monoclonal antibodies for the unphosphorylated and phosphorylated forms of Src (phosphorylation of tyrosine 416) and focal adhesion kinase (FAK) (phosphorylation of tyrosine 576/577) were purchased from Cell Signaling Technology, Inc., to evaluate the activation status of the Src/FAK signaling pathway. Anti-GAPDH (Beyotime Institute of Biotechnology) was used to detect GAPDH, which served as the internal reference.

Cell counting Kit-8 (CCK-8). Cells were seeded onto a 96-well plate at $2 \times 10^{3}$ cells/well. Following $24 \mathrm{~h}$ of incubation, the cells were stimulated with $50 \mathrm{nmol} / 1$ of CX3CL1 in the experimental group. In the control group, the same amount of distilled water was added to the wells. After 1, 2 and 3 days, CCK-8 (Dojindo Molecular Technologies, Inc., Kumamoto, Japan) was added to the corresponding wells, and the plate was incubated at $37^{\circ} \mathrm{C}$ for $2 \mathrm{~h}$. A multi-well spectrophotometer was used to measure the absorbance at $450 \mathrm{~nm}$.

In vitro migration and invasion assay. The migration and invasion assays were performed using 24-well Transwell chambers with $8-\mu \mathrm{m}$ pores (Corning Incorporated, Corning, NY, USA); however, the chambers were coated with Matrigel for the invasion assay.

Briefly, after extensive washing, $3 \times 10^{4}$ (migration assay) or $6 \times 10^{4}$ (invasion assay) cells were suspended in DMEM without FBS and plated on each upper chamber. The lower chambers were filled with DMEM containing 0.1\% bovine serum albumin, which was supplemented with or without $100 \mathrm{nmol} / \mathrm{l}$ of CX3CL1. For inhibition of the assays, the upper chambers were treated with $100 \mathrm{nmol} / 1$ of saracatinib for $1 \mathrm{~h}$ prior to the assays. Following $24 \mathrm{~h}$ of incubation at $37^{\circ} \mathrm{C}$, the cells in the upper chamber of the membrane were removed with a cotton swab, and the cells on the underside were fixed with paraformaldehyde and stained with $0.1 \%$ crystal violet. 


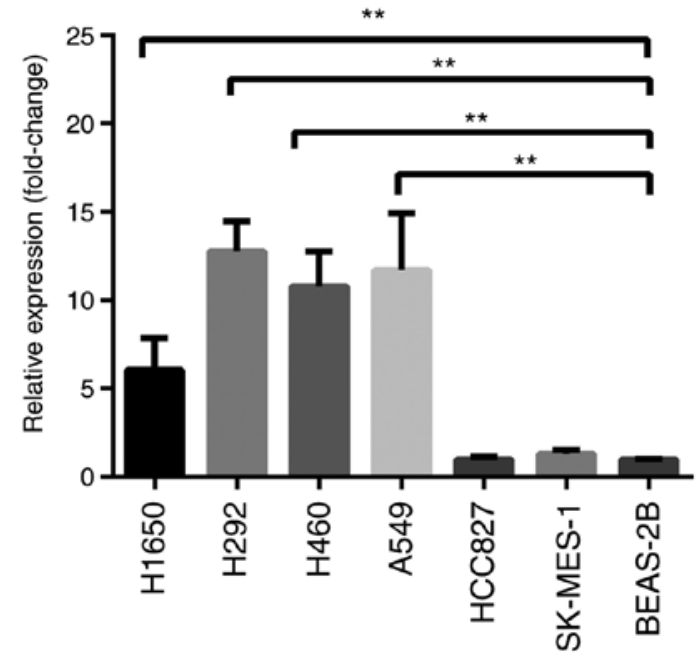

Figure 1. Expression of CX3CR1 mRNA in cell lines. H1650, H292, H460, A549 contained higher levels of CX3CR1 mRNA than BEAS-2B. Data were presented as the mean \pm standard deviation $(\mathrm{N}=3)$. ${ }^{* *} \mathrm{P}<0.01$ as indicated. CX3CR1, C-X3-C motif chemokine receptor 1.

The cells were counted in three randomly selected fields under light microscope (magnification, x40).

Statistical analysis. Data were expressed as the mean \pm standard deviation. Significant differences were identified using the one-way analysis of variance with subsequent use of post hoc LSD tests to differentiate between two groups when needed.
$\mathrm{P}<0.05$ was considered to indicate a statistically significant difference.

\section{Results}

Expression of CX3CR1 in the cell lines. RT-qPCR and western blotting were used to analyze CX3CR1 mRNA and protein expression levels, respectively. RT-qPCR results revealed that the CX3CR1 mRNA levels were significantly increased in the H1650, H292, H460 and A549 cells compared with BEAS-2B cells (Fig. 1). The protein expression levels of CX3CR1 were significantly increased in all six lung cancer cell lines when compared with BEAS-2B (Fig. 2). Notably, the two CX3CR1 bands exhibited in Fig. 2A can be attributed to various factors. Firstly, CX3CR1 may have isomers. Secondly, there was slight degradation of CX3CR1 during detection. The upper band with the anticipated molecular mass was used to calculate the expression. Notably, there was a discrepancy between the expression levels of CX3CR1 mRNA and protein. Based on the data from both evaluations, H460 was selected for further study. Furthermore, the cell membrane was not permeated by $0.1 \%$ Triton X-100. Therefore, the signal represented the cell surface CX3CR1 expression (Fig. 2C).

Impact of $C X 3 C L 1$ on tumor cell proliferation. To investigate whether CX3CL1 has a direct impact on tumor cell proliferation, the CCK-8 assay was used to evaluate the growth of H460 with and without CX3CL1. As indicated in Fig. 3, CX3CL1 did not significantly affect the proliferative capacity of $\mathrm{H} 460$.
A

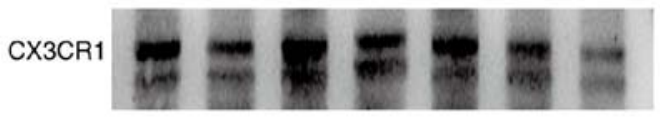

Tubulin

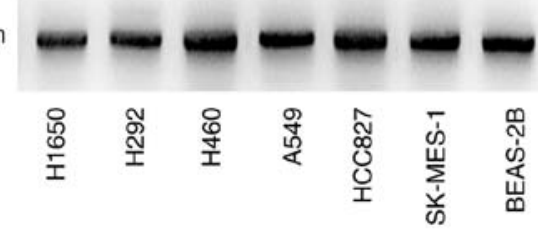

B

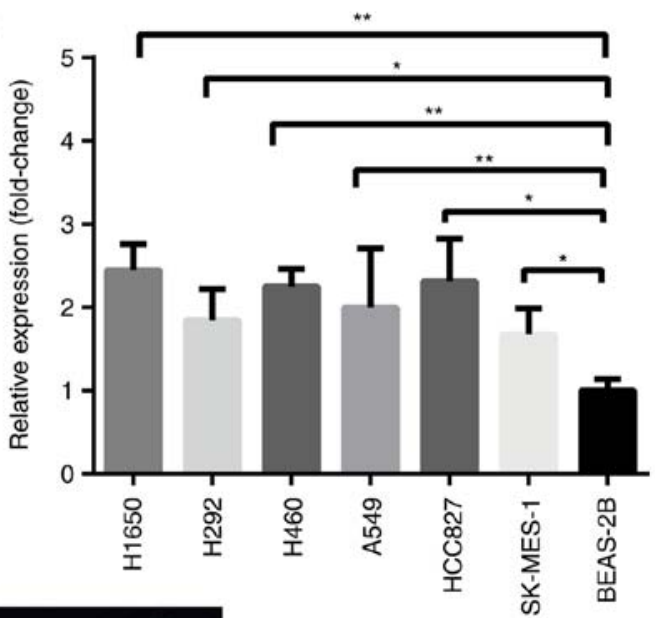

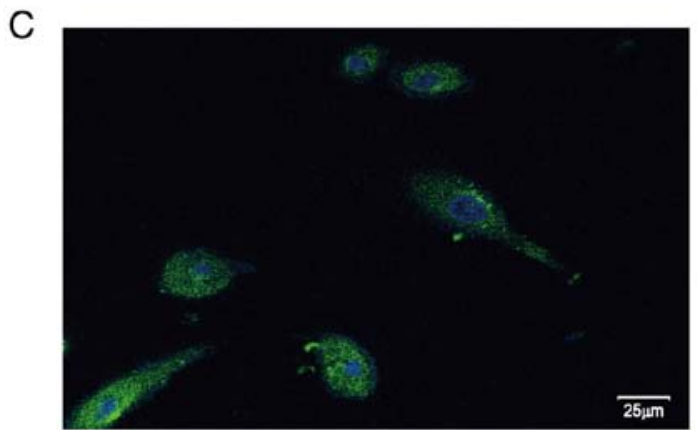

Figure 2. Expression of CX3CR1 protein in cell lines. According to the molecular mass of CX3CR1, the upper band in CX3CR1 was used to calculate expression. (A and B) CX3CR1 was highly expressed in the lung cancer cell lines compared with BEAS-2B. (C) Cell surface CX3CR1 expression was detected using the immunofluorescence combined with Hoechst staining for $\mathrm{H} 460$ nuclei. Data were presented as the mean \pm standard deviation $(\mathrm{N}=3)$. ${ }^{*} \mathrm{P}<0.05$ and ${ }^{* *} \mathrm{P}<0.01$ as indicated. CX3CR1, C-X3-C motif chemokine receptor 1. 


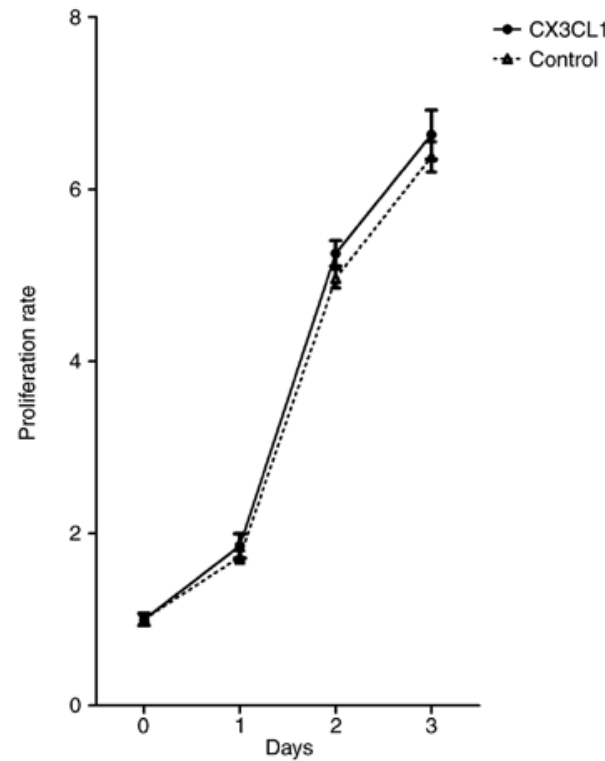

Figure 3. Proliferation rate of $\mathrm{H} 460$ with and without CX3CL1. There was no significant difference in the proliferation rate between the two groups. Data were presented as the mean \pm standard deviation $(\mathrm{N}=3)$. CX3CL1, C-X3-C motif chemokine ligand 1 .

Impactontumor cellmovement. As indicated in Fig.4,Transwell invasion and migration assays were performed. Compared with the cells without stimulation of CX3CL1, the migration and invasion abilities of $\mathrm{H} 460$ were significantly increased following $24 \mathrm{~h}$ of exposure to CX3CL1 (Fig. 4A-C and G). However, saracatinib significantly inhibited the enhanced CX3CL1-induced migration and invasion abilities of H460 to lower than basal level (Fig. 4D-F and H). Notably, CX3CL1 did not elicit a significant response in H292 and A549 cells (data not shown).

CX3CL1-induced activation of the Src/FAK pathway. To obtain evidence that CX3CL1 promoted $\mathrm{H} 460$ cell migration and invasion via the Src/FAK signaling pathway, the phosphorylation of Src and FAK was analyzed in CX3CL1-stimulated cells. In this experiment, CX3CL1-induced Src phosphorylation peaked 15 min post-stimulation. In addition, CX3CL1-induced FAK phosphorylation peaked $30 \mathrm{~min}$ post-stimulation (Fig. 5A). However, saracatinib hindered CX3CL1-induced Src and FAK phosphorylation (Fig. 5B).

\section{Discussion}

Although the CX3CL1-CX3CR1 interaction is well known in the metastatic process of variety of cancer types, the present study provided insight into the role of CX3CL1 as an enhancer of metastasis in lung cancer. The present findings provided evidence that CX3CL1 promotes the chemotaxis ability of lung cancer cells by binding to CX3CR1 and activating the Src/FAK signaling pathway.
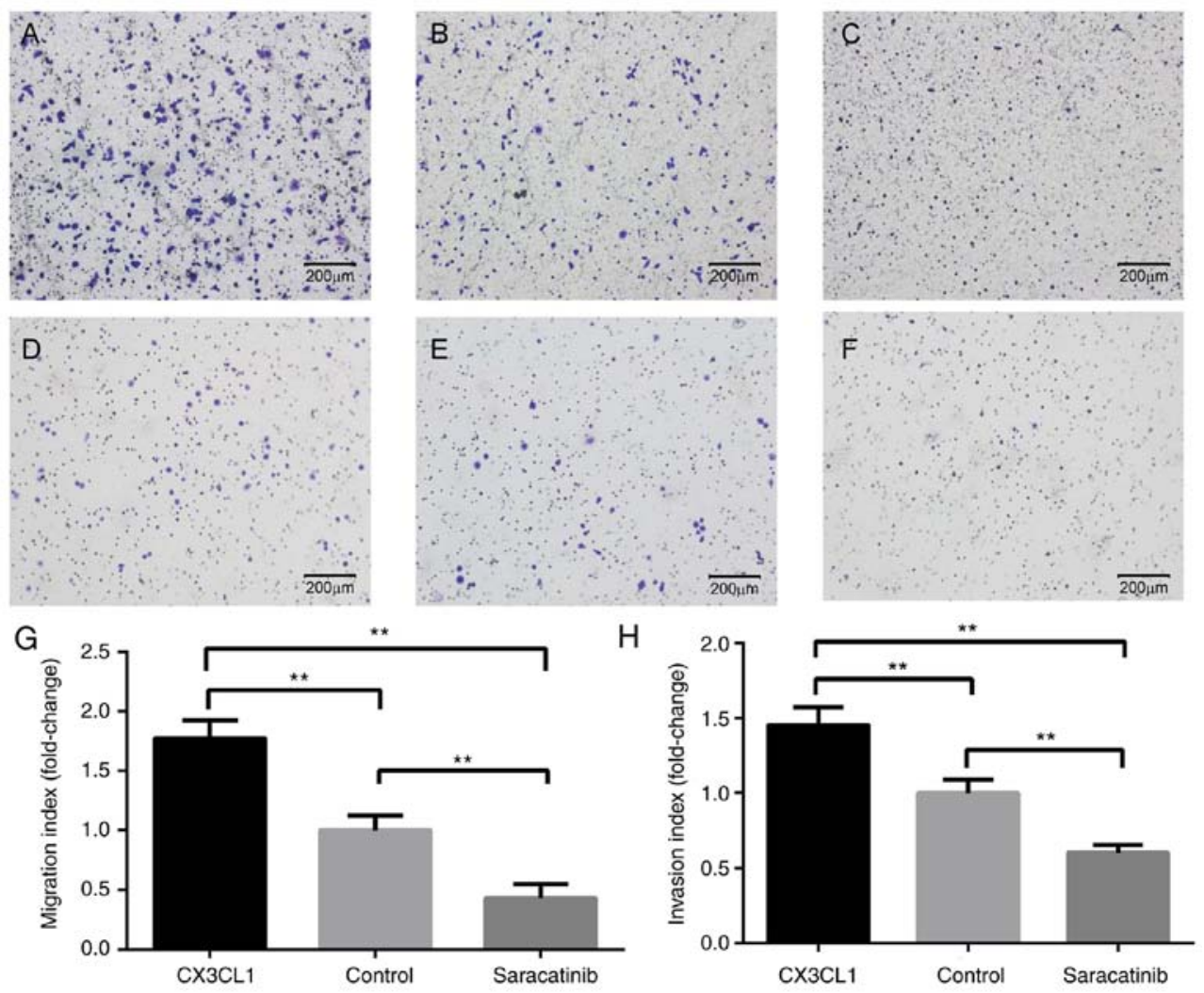

Figure 4. Cell invasion and migration assays. Representative images of H460 cell migration, following treatment (A) with or (B) without CX3CL1, were captured (magnification, x100). (C) H460 was incubated with saracatinib during CX3CL1-stimulated migration. Representative images of H460 cell invasion, following treatment (D) with and (E) without CX3CL1, were captured (magnification, x100). (F) H460 was incubated with saracatinib during CX3CL1-stimulated invasion. Quantitative results for the $(\mathrm{G})$ migration and $(\mathrm{H})$ invasion assays were indicated. The migration and invasion indices were calculated as the number of migrated cells compared to that of control group. Data were presented as the mean \pm standard deviation $(\mathrm{N}=3){ }^{* *} \mathrm{P}<0.01$ as indicated. CX3CL1, $\mathrm{C}-\mathrm{X} 3-\mathrm{C}$ motif chemokine ligand 1 . 
A

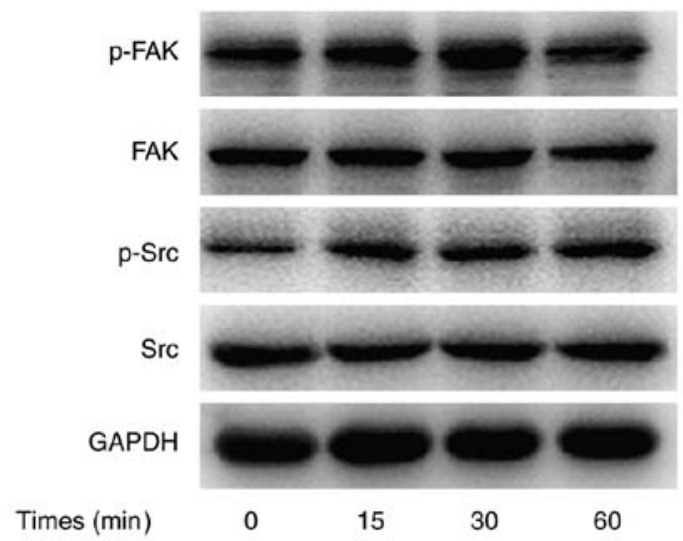

B

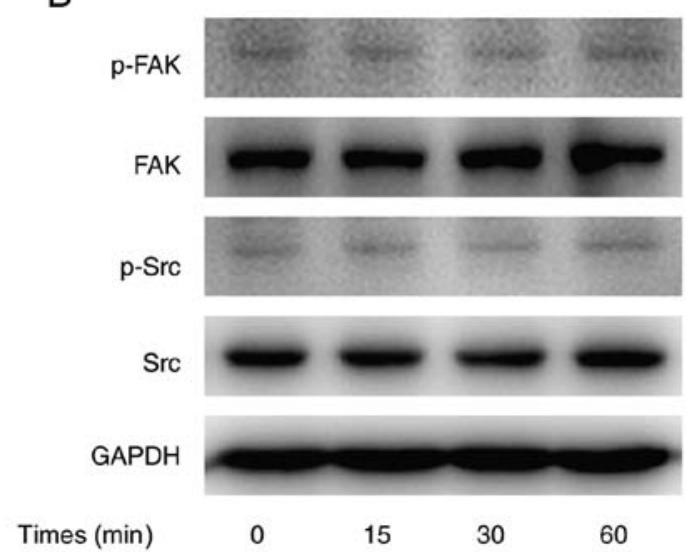

Figure 5. CX3CL1 activates the Src/FAK signaling pathway in H460. CX3CL1 induced (A) Src and FAK phosphorylation, which peaked at either 15 min or 30 min after stimulation, respectively. (B) Pre-treatment of H460 with Saracatinib abrogated Src and FAK phosphorylation. FAK, focal adhesion kinase; CX3CL1, C-X3-C motif chemokine ligand 1.

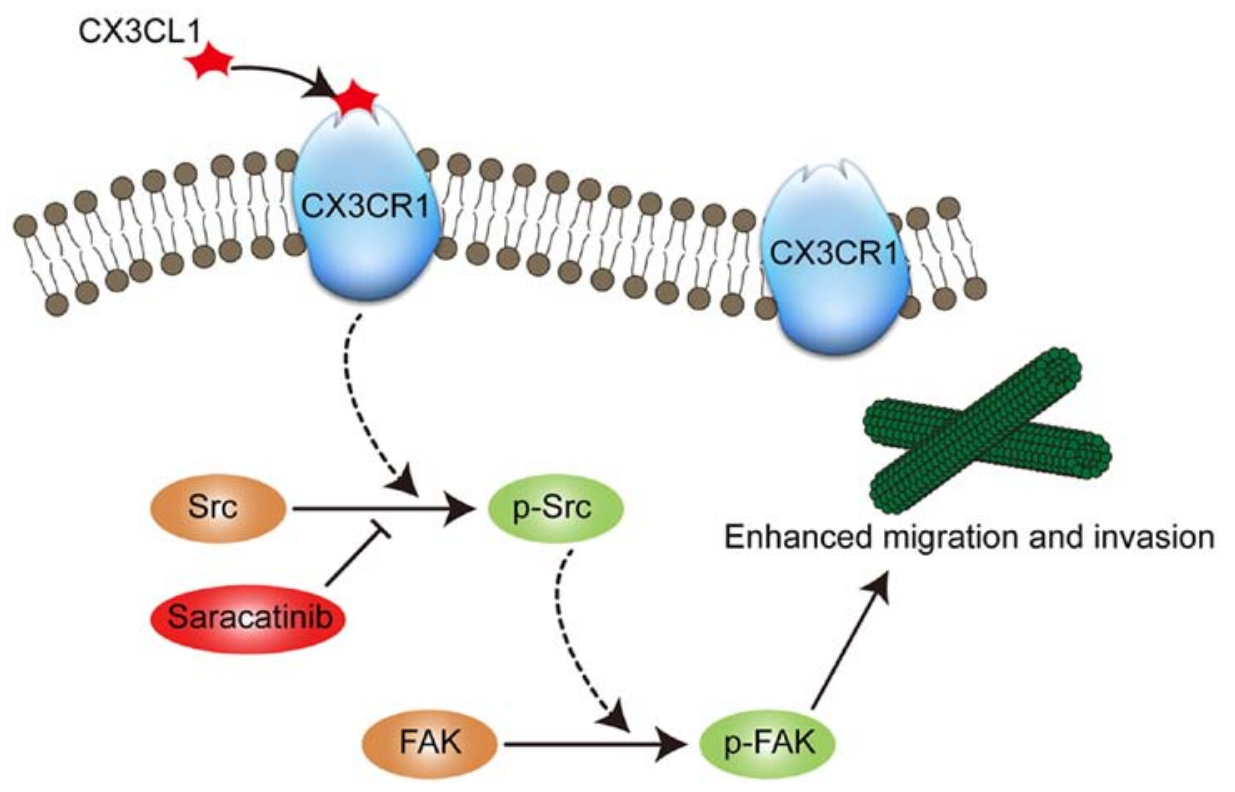

Figure 6. Model of CX3CL1-enhanced lung cancer cell chemotaxis ability. CX3CL1 may promote the chemotaxis ability of lung cancer cells by enhancing the Src/FAK signaling pathway. Saracatinib could abrogate the effect of CX3CL1 on chemotaxis. CX3CL1, C-X3-C motif chemokine ligand 1; CX3CR1, C-X3-C motif chemokine receptor 1; FAK, focal adhesion kinase.

The precursor of CX3CL1 is synthesized as an intracellular $50-75 \mathrm{kDa}$ protein that is rapidly processed and transported to the cell surface (20). A soluble $85-\mathrm{kDa}$ fragment of CX3CL1, containing a 76-amino acid chemokine domain, can be cleaved from the cell surface under normal growth conditions. However, this process may be accelerated by stimuli, such as cancer (21). Therefore, under physiological and pathological conditions, CX3CL1 is allowed to mediate the chemotaxis and firm capture of CX3CR1-expressing cells via the soluble and membrane-attached form of CX3CL1, respectively (22). CX3CR1, a seven-transmembrane G-protein-coupled receptor, mediates the activation of the downstream signaling pathway (c-Raf, mitogen-activated protein kinase kinase, extracellular signal-regulated kinase and nuclear factor- $\kappa \mathrm{B}$ ) through its ligand, CX3CL1 (23).
The present study investigated CX3CR1 expression at mRNA and protein levels. Although all six lung cancer cell lines demonstrated overexpression of CX3CR1 at protein levels, some of the lung cancer cells lines were not upregulated at mRNA levels. The discrepancy between the mRNA and protein expression levels may be due to posttranscriptional and posttranslational control mechanisms. Thus, the amount and frequency of protein synthesis may not simply coincide with the amount of mRNA (24). Since H460 exhibited higher CX3CR1 expression at mRNA and protein levels, this cell line was selected for further experiments in the present study.

To study the potential effects of CX3CL1 on lung cancer cell proliferation, the proliferation rate of $\mathrm{H} 460$ with and without CX3CL1 was assessed using CCK-8 in vitro. No significant differences were observed between the two groups. However, Tardaguila et al (25) reported that CX3CL1 
contributes to tumorigenesis in breast cancer. Through proteolytic shedding of an ErbB ligand, CX3CL1 triggered cell proliferation by transactivating the ErbB receptors. Thus, the increased tumor multiplicity was a consequence of CX3CL1 acting as a positive modifier of breast cancer in concert with ErbB receptors rather than CX3CL1-induced metastatic dissemination of the primary tumor (25). This inconformity may be associated with the different molecular mechanisms of tumor heterogeneity.

Based upon the observations from the in vitro migration and invasion assays in the present study, CX3CL1 significantly promoted the chemotaxis ability of lung cancer cells. Notably, the results were negative for $\mathrm{H} 292$ and A549 cells, which can be attributed to tumor heterogeneity. Furthermore, the present study revealed that the molecular mechanisms, following CX3CL1 activation in lung cancer cells, involved the Src/FAK signaling pathway. Src, a proto-oncogene, is a non-receptor protein-tyrosine kinase that is a critical regulator of signal transduction induced by a variety of cell-surface receptors. Src serves a key role in cell growth, division, migration and survival signaling pathways. Furthermore, Src activity is regulated by tyrosine phosphorylation of two chief sites, pTyr416 and pTyr530. Phosphorylation of Tyr416, located in the activation loop of the kinase domain, by an adjacent Src molecule results in upregulated enzyme activity. However, phosphorylation of Tyr530, located in the regulatory tail, by C-terminal Src kinase or Csk homologous kinase renders the enzyme less active $(26,27)$. FAK is another subgroup of the non-receptor protein tyrosine kinases, and it is regulated by phosphorylation and dephosphorylation. FAK has been identified to participate, through various pathways, in a diverse spectrum of receptor-induced biological activities, particularly the activation of cell spreading and migration through integrin-mediated signal transduction (28). Specifically, integrin clustering results in the phosphorylation of Tyr397, which prepares the binding site for Src family kinases. Following this, the recruitment of Src family kinases leads to the phosphorylation of Tyr576/577 in the catalytic domain (29). Therefore, when deregulated, the Src/FAK complex indicates strong oncogenic activity. Based on the present study, a model was proposed in which CX3CL1-CX3CR1 interaction first phosphorylates Src at Tyr416. Subsequently, the phosphorylated Src binds with FAK and phosphorylates FAK at Tyr576/577 (Fig. 6). Saracatinib, a Src inhibitor, could abrogate the effect of CX3CL1 on chemotaxis. Saracatinib has also been reported to inhibit cell movement in prostate cancer (30) and bladder cancer (31), which is consistent with the present study. Therefore, saracatinib may translate as a clinical therapy that inhibits cancer metastasis; however, further studies are required.

In conclusion, CX3CL1 enhanced the migration and invasion of lung cancer cells. It was proposed that the Src/FAK signaling pathway is involved in CX3CL1-CX3CR1 interaction, which causes enhanced migration and invasion. The present results also highlight the potent anti-migratory and anti-invasive effects of saracatinib in vitro.

\section{Acknowledgements}

Not applicable.

\section{Funding}

The present study was supported by the National Natural Science Foundation of China (grant no. 81572629).

\section{Availability of data and materials}

The analyzed data sets generated during the study are available from the corresponding author on reasonable request.

\section{Authors' contributions}

JD conceived the study and revised the manuscript. WL and YL performed the experiments and wrote the manuscript. QC and $\mathrm{LJ}$ collected and analyzed the data. All authors read and approved the final manuscript.

\section{Ethics approval and consent to participate}

Not applicable.

\section{Patient consent for publication}

Not applicable.

\section{Competing interests}

The authors declare that they have no competing interests.

\section{References}

1. Jemal A, Bray F, Center MM, Ferlay J, Ward E and Forman D: Global cancer statistics. CA Cancer J Clin 61: 69-90, 2011.

2. Chen W, Zheng R, Zeng H and Zhang S: Epidemiology of lung cancer in China. Thorac Cancer 6: 209-215, 2007.

3. Arriagada R, Bergman B, Dunant A, Le Chevalier T, Pignon JP and Vansteenkiste J; International Adjuvant Lung Cancer Trial Collaborative Group: Cisplatin-based adjuvant chemotherapy in patients with completely resected non-small-cell lung cancer. N Engl J Med 350: 351-360, 2004

4. Wang T, Nelson RA, Bogardus A and Grannis FW Jr: Five-year lung cancer survival: Which advanced stage nonsmall cell lung cancer patients attain long-term survival? Cancer 116: 1518-1525, 2010.

5. Luster AD: Chemokines-chemotactic cytokines that mediate inflammation. N Engl J Med 338: 436-445, 1998.

6. Harrison JK, Fong AM, Swain PA, Chen S, Yu YR, Salafranca MN Greenleaf WB, Imai T and Patel DD: Mutational analysis of the fractalkine chemokine domain. Basic amino acid residues differentially contribute to CX3CR1 binding, signaling, and cell adhesion. J Biol Chem 276: 21632-21641, 2001.

7. Ludwig A and Weber C: Transmembrane chemokines: Versatile 'special agents' in vascular inflammation. Thromb Haemost 97: 694-703, 2007.

8. Bazan JF, Bacon KB, Hardiman G, Wang W, Soo K, Rossi D, Greaves DR, Zlotnik A and Schall TJ: A new class of membranebound chemokine with a CX3C motif. Nature 385: 640-644, 1997.

9. Haskell CA, Cleary MD and Charo IF: Unique role of the chemokine domain of fractalkine in cell capture. Kinetics of receptor dissociation correlate with cell adhesion. J Biol Chem 275: 34183-34189, 2000.

10. Fonovic UP, Jevnikar Z and Kos J: Cathepsin $\mathrm{S}$ generates soluble CX3CL1 (fractalkine) in vascular smooth muscle cells. Biol Chem 394: 1349-1352, 2013.

11. Marchesi F, Locatelli M, Solinas G, Erreni M, Allavena P and Mantovani A: Role of CX3CR1/CX3CL1 axis in primary and secondary involvement of the nervous system by cancer. J Neuroimmunol 224: 39-44, 2010. 
12. Tsang JY, Ni YB, Chan SK, Shao MM, Kwok YK, Chan KW, Tan PH and Tse GM: CX3CL1 expression is associated with poor outcome in breast cancer patients. Breast Cancer Res Treat 140 495-504, 2013

13. Andre F, Cabioglu N, Assi H, Sabourin JC, Delaloge S, Sahin A, Broglio K, Spano JP, Combadiere C, Bucana C, et al: Expression of chemokine receptors predicts the site of metastatic relapse in patients with axillary node positive primary breast cancer. Ann Oncol 17: 945-951, 2006.

14. Zheng J, Yang M, Shao J, Miao Y, Han J and Du J: Chemokine receptor CX3CR1 contributes to macrophage survival in tumor metastasis. Mol Cancer 12: 141, 2013

15. Kim M, Rooper L, Xie J, Kajdacsy-Balla AA and Barbolina MV: Fractalkine receptor $\mathrm{CX}_{3} \mathrm{CR} 1$ is expressed in epithelial ovarian carcinoma cells and required for motility and adhesion to peritoneal mesothelial cells. Mol Cancer Res 10: 11-24, 2012.

16. Shulby SA, Dolloff NG, Stearns ME, Meucci O and Fatatis A: CX3CR1-fractalkine expression regulates cellular mechanisms involved in adhesion, migration, and survival of human prostate cancer cells. Cancer Res 64: 4693-4698, 2004

17. Celesti G, Di Caro G, Bianchi P, Grizzi F, Marchesi F, Basso G, Rahal D, Delconte G, Catalano M, Cappello P, et al: Early expression of the fractalkine receptor CX3CR1 in pancreatic carcinogenesis. Br J Cancer 109: 2424-2433, 2013.

18. Yao X, Qi L, Chen X, Du J, Zhang Z and Liu S: Expression of CX3CR1 associates with cellular migration, metastasis, and prognosis in human clear cell renal cell carcinoma. Urol Oncol 32: 162-170, 2014.

19. Livak KJ and Schmittgen TD: Analysis of relative gene expression data using real-time quantitative PCR and the $2^{-\Delta \Delta C_{\mathrm{T}}}$ method. Methods 25: 402-408, 2001.

20. Garton KJ, Gough PJ, Blobel CP, Murphy G, Greaves DR, Dempsey PJ and Raines EW: Tumor necrosis factor-alphaconverting enzyme (ADAM17) mediates the cleavage and shedding of fractalkine (CX3CL1). J Biol Chem 276: 37993-38001, 2001.

21. Shiraishi K, Fukuda S, Mori T, Matsuda K, Yamaguchi T, Tanikawa C, Ogawa M, Nakamura Y and Arakawa H: Identification of fractalkine, a CX3C-type chemokine, as a direct target of p53. Cancer Res 60: 3722-3726, 2000.
22. Imai T, Hieshima K, Haskell C, Baba M, Nagira M,Nishimura M, Kakizaki M, Takagi S, NomiyamaH, Schall TJ, et al: Identification and molecular characterization of fractalkine receptor $\mathrm{CX}_{3} \mathrm{CR} 1$, which mediates both leukocyte migration and adhesion. Cell 91: 521-530, 1997.

23. Hou SM, Hou CH and Liu JF: CX3CL1 promotes MMP-3 production via the CX3CR1, c-Raf, MEK, ERK, and NF- $\kappa \mathrm{B}$ signaling pathway in osteoarthritis synovial fibroblasts. Arthritis Res Ther 19: 282, 2017.

24. Ideker T, Thorsson V, Ranish JA, Christmas R, Buhler J, Eng JK, Bumgarner R, Goodlett DR, Aebersold R and Hood L: Integrated genomic and proteomic analyses of a systematically perturbed metabolic network. Science 292: 929-934, 2001.

25. Tardaguila M, Mira E, Garcia-Cabezas MA, Feijoo AM, Quintela-Fandino M, Azcoitia I, Lira SA and Mañes S: CX3CL1 promotes breast cancer via transactivation of the EGF pathway. Cancer Res 73: 4461-4473, 2013.

26. Thomas SM and Brugge JS: Cellular functions regulated by $\mathrm{Src}$ family kinases. Annu Rev Cell Dev Biol 13: 513-609, 1997.

27. Roskoski R Jr: Src protein-tyrosine kinase structure, mechanism, and small molecule inhibitors. Pharmacol Res 94: 9-25, 2015.

28. Parsons JT, Martin KH, Slack JK, Taylor JM and Weed SA Focal adhesion kinase: A regulator of focal adhesion dynamics and cell movement. Oncogene 19: 5606-5613, 2000.

29. Zhang X, Chattopadhyay A, Ji QS, Owen JD, Ruest PJ, Carpenter G and Hanks SK: Focal adhesion kinase promotes phospholipase C-gamma1 activity. Proc Natl Acad Sci USA 96: 9021-9026, 1999.

30. Chang YM, Bai L, Liu S, Yang JC, Kung HJ and Evans CP. Src family kinase oncogenic potential and pathways in prostate cancer as revealed by AZD0530. Oncogene 27: 6365-6375, 2008.

31. Green TP, Fennell M, Whittaker R, Curwen J, Jacobs V, Allen J, Logie A, Hargreaves J, Hickinson DM, Wilkinson RW, et al: Preclinical anticancer activity of the potent, oral Src inhibitor AZD0530. Mol Oncol 3: 248-261, 2009. 